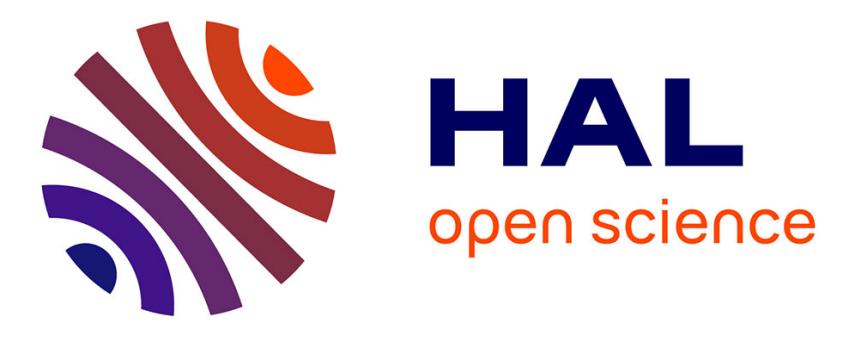

\title{
Multi-facilities tactical planning robustness with experimental design
}

Patrick Genin, Samir Lamouri, André Thomas

\section{To cite this version:}

Patrick Genin, Samir Lamouri, André Thomas. Multi-facilities tactical planning robustness with experimental design. Production Planning and Control, 2008, 19 (2), pp.171-182. 10.1080/09537280801896250 . hal-00121146

\section{HAL Id: hal-00121146 \\ https://hal.science/hal-00121146}

Submitted on 19 Dec 2006

HAL is a multi-disciplinary open access archive for the deposit and dissemination of scientific research documents, whether they are published or not. The documents may come from teaching and research institutions in France or abroad, or from public or private research centers.
L'archive ouverte pluridisciplinaire HAL, est destinée au dépôt et à la diffusion de documents scientifiques de niveau recherche, publiés ou non, émanant des établissements d'enseignement et de recherche français ou étrangers, des laboratoires publics ou privés. 
YYY, Vol. X, No. X, Month 2005, xxx-xxx

\section{Multi-facilities tactical planning robustness with experimental design}

\section{P. GENIN*†, S. LAMOURI $\dagger$ and A.THOMAS}

$\dagger$ Lab. of Integrated Engineering of Mechanical Systems and Materials LISMMA (EA2336) - 3, rue Fernand Hainaut - 93407 Saint-Ouen CEDEX France

$\S$ Research Centre for Automatic Control of Nancy (UMR7039) - Faculté des sciences BP239 - 54506 - VANDOEUVRE les NANCY

*Corresponding author. Email: patrick.genin@supmeca.fr

This paper addresses the problem of tactical planning robustness of a three-level multifacilities supply chain. Robustness of uncontrollable factors such as demand is an increasing concern because of the key role played in supply chain planning. This study aims at proposing an approach based on an experimental design and the use of signal/noise ratio as developed by Taguchi when establishing tactical plans. LP model, such as those used in advanced planning systems, is developed to solve tactical planning concerns. By adjusting policy parameters, such as overtime, inventory level costs, and so on, decisionmaker can determine an optimal tactical plan while considering the robustness to uncertain demand. This approach enhances the compromise between minimized costs and improved robustness. This methodology has been applied on a case study of an aggregate plan based on a Vallourec steel tube company.

Keywords: Supply chain planning; tactical planning; robustness; process modeling; APS systems.

\section{Introduction}

Recent years have witnessed increasing interest in supply chain (SC) management problems (Croom et al. 2000). However, no sufficient attention has been paid to planning and control models and performance measurements of these new structures for which 


\section{P. Genin et al.}

coordination is more important (Walters 2005). Previously, industrial dynamics theory had been used to examine SC dynamic behaviour (Forrester 1961, Towill 1991). Forrester proved that small variations in customer demand caused demand variations amplification along an SC and created system instability. This phenomenon is called the "bullwhip effect." One of the root causes of the bullwhip effect is the use of inadequate forecasting methods, which do not correctly quantify the degree of uncertainty in the market demand (Chen et al. 1998).

Supply chain planning Systems (SCPS) processes the information on demand and turns it into coordinated signals for all the supply chain entities. These signals are relayed to the supply chain partners through private or public network (Vollmann et al. 1997). SCPS play a key role in propagating the amplified signal on demand and uncertainty.

Landeghem and Vanmaele argue that tactical planning is the most appropriate level in a supply chain planning system to provide buffers against uncertainty based on the time period over which they fluctuate (Landeghem and Vanmaele 2002). On the one hand, the SC infrastructure is fixed by strategic level. On the other hand, there is often insufficient time to react to demand variations at the operational level because of the planning constraints. They conclude that demand uncertainty can be handled best at the tactical level. Tactical levels set the global quantities through the supply chain as well as the availability of the resources in SC. The tactical plan compares alternatives and various indicators aggregated in weighted-cost functioning and selects the best plan (Vollmann et al. 1997). Decisions on inventories, transportation, production, and capacity are simultaneously discussed as a trade-off between costs. Important results are the planned capacity and the level of seasonal inventory. These decisions cannot be made by short-term scheduling 


\section{Multi-facilities Tactical Planning Robustness}

because of a shorter planning horizon. Supposing a linear relationship among costs, quantities, and constant parameters, that kind of decision making can easily be modelled by linear programming (LP). Advanced planning systems (APS) widely use these techniques to optimize tactical plan models (Fleischmann et al. 2000).

LP is a method known to be sensitive to changes in parameters. Sensitivity analysis, used in this context, determines parameter ranges for which a solution remains optimal (Koltaï and Terlaky 2000). However, it studies each parameter while keeping the others unchanged. The manager cannot study suboptimal but less sensitive solutions of the simultaneous variations of the factors. Moreover, few APS give such information (Stadtler and Kilger 2000). So, these parameters and weights representing managers' policies have to be set properly in order to increase decisions' robustness.

Stochastic programming could be used to maximize or minimize the expected value of our objective function as Leung proved (Leung and $\mathrm{Wu}$ 2004), but such an approach still does not succeed in solving general, real-sized problems (Mulvey and Ruszczynski 1995).

In supply chains where costs are a primary focus and flexibility is limited, one important factor in cost containment is the reduction of the number of schedule changes and an increase in planning robustness. The way uncertainty is processed by SCPS needs to be addressed more effectively. In this paper, we propose a planning process that improves robustness of tactical plan costs subject to controllable and uncontrollable parameters.

Taguchi worked out a method using fractional plans. It makes it possible to determine the effects of the factors of a system easily (see Figure 1) (Taguchi 1987). By using the Taguchi method, we can offer a robust optimal solution to uncontrollable factors such as demand.

[Insert figure 1 about here] 
P. Genin et al.

This paper is organized as follows. In the next section, an SC structure and a tactical planning process are defined. Measures and approaches of robustness are discussed in Section 3. In Section 4, a generic LP model is developed. The tactical planning simulator that incorporates the LP model is presented. The case study, experimental design, and results are analyzed in Section 5.

\section{Supply chain description and tactical planning process}

We first describe the general SC structure considered in this article and then specify the tactical planning process we plan to model.

\subsection{Supply chain structure}

The studied SC is a three-level multi-facilities SC producing $q$ finished goods, $g=1, \ldots, q$ (see Figure 2). It is composed of the following:

- $n$ suppliers plants, $s=1, \ldots, n$

- $m$ plants, $p=1, \ldots, m$

- o warehouses, $w=1, \ldots, o$

These $q$ finished goods are produced in the $m$ plants from $q$ critical components produced and supplied by the $n$ suppliers from one raw material. A raw material is used to make a component. It takes one period to produce a component from a raw material and a finished good from a component. Transportation lead time is one period.

Each supplier's and plant's production is constrained by the number of working hours, material availability, and storage capacity. Warehouses can store a limited number of finished goods because of bulk constraints.

[Insert figure 2 about here] 
Multi-facilities Tactical Planning Robustness

\subsection{Tactical planning process}

[Insert figure 3 about here]

A simplified tactical planning process is shown in Figure 3. At each rescheduling cycle, new forecasts are established according to the modifications in demand for the first period. Then all the decision variables (inventory, backorders, transported quantities, production level, operators and overtime) are adjusted by optimization of an LP model such as those used in advanced planning systems. This model is formulated in section 4 . The new plan maximises profitability, but is not concerned with modifications made in the productiondistribution and supply plans. These practices induce strong disturbances on the productive system and on the partners in the SC by generating the bullwhip effect. The overcosts created by these variations are not taken into account in the global optimization of the system.

\section{Stability and robustness measures}

In order to quantify robustness, several approaches are possible.

\subsection{Stability definition}

One approach tries to find a decision policy that reduces the number of changes to the plan while keeping the key performance measures fixed at their target level. This approach was used to deal with Material Requirements Planning (MRP) "nervousness" to improve plan “stability" (Blackburn et al. 1986, Yano and Carlson 1987, Ho 1989, Minifie and Davis 1990, Sridaharan and Laforge 1990, Jensen 1993, Kadipasaoglu and Sridharan 1995, Heisig 1998). For example, Kadipasaoglu and Sridharan show the difficulties induced by the nervousness because of uncertainty in demand, purchasing or in the dynamic 


\section{P. Genin et al.}

calculation of lot size in MRP systems (Kadipasaoglu and Sridharan, 1995). "Nervousness" has been defined as a lack of stability in the material requirements planning (Orlicky 1975, De Kok and Inderfurth 1997). Donselaar et al. (2000) compare the nervousness of the plan generated by MRP with that of their heuristic to improve stability of purchased orders. The considered indicator is the number of "reschedulings" encountered within the periods: if a quantity appears or disappears during a period, the indicator is incremented; however, if quantities are only modified, the indicator remains at the same level. The instability of a plan is defined by the number of modifications made on the levels of decision variables between two successive versions of the plan (Pujawan 2004).

The term "stability" is thus related to the number of changes in a plan from one generation to the next. Depending on planning typology, the stability indicator can be linked to one or more different decision variables.

Several strategies have been proposed to increase the stability of plans using MRP systems:

- extend the planning horizon (Carlson 1982),

- freeze the master schedule within the planning horizon (Zhao and Lee 1993),

- ensure that buffer or safety stocks are in place (Blackburn et al. 1986),

- differentiate between large and small modifications (Ho 1989).

\subsection{Robustness definition}

Another approach tries to find the policy that yields the most stable outcome, that is, with low variability of the key performance measures such as service level or total supply chain inventory (Lee and Yu 1997).

The term "robustness" is generally associated with that of "risk" and "decision making" (Kleijnen and Gaury 2003, Durieux and Pierreval 2003). The underlying idea of system robustness is generally that the measured functions do not diverge significantly from a 
given value (Mulvey et al. 1995, Yu and Li 2000). Robustness is calculated by the standard deviation of each of the measured indicators.

The most common approach when studying robustness of a system is the well known Taguchi method (Taguchi 1987). Its main principle is the following: instead of trying to eliminate or to reduce the causes for product (or process) performance variability, it aims at adjusting the design of a product (or a process), so that it is insensitive to the effects of uncontrollable variations (Fowlkes and Creveling 1997). Taguchi's methodology is based on the use of crossed designs of experiments and a quadratic loss function or a signal to noise ratio $(\mathrm{S} / \mathrm{N})$. This $\mathrm{S} / \mathrm{N}$ ratio takes into account both the variability in the response data and the closeness of the average response to a target value (Mezgar et al. 1997). The higher this indicator, the better the compromise is. It can be calculated in different ways depending on the situation: function to minimize, to maximize, or to reach a target.

Robustness studies and some approaches have been proposed in several areas such as quality management, manufacturing design (Lim et al. 1996, Durieux and Pierreval 2003), scheduling (Davenport and Beck 2000, Artigues et al. 2005), control policies of production system (Kleijnen and Gaury 2003) or operational design of supply chain (Shang et al. 2004). However, in our knowledge, there is no work on robustness consideration when constructing tactical plan of supply chain network.

Several definitions exist for "robustness" of tactical plan. Zäpfel (Zäpfel 1998) and Roy (Roy 1998) consider a tactical plan as robust if an operational plan can be calculated for all the possible sets of demand. This definition is used by Lasserre and Mercé (Lasserre and Mercé 1990) in their work on plans breakdown. 


\section{P. Genin et al.}

In a very different context from ours, Kleijnen and Gaury study the robustness of a kanban loop according to two functions: the expected value of the work-in-process and the delivery rate (Kleijnen and Gaury 2003). In our study, the robustness of the tactical plan will be calculated by the standard deviation of the sum of the costs of decisions implemented at each period, because one of the main objectives of tactical planning is to be coherent about budgeting. Other performance indicators could have been chosen according to different planning typologies:

- Net margin

- Capital in inventories or safety stock level

- Service level and so on

- $\quad .$.

As in our problem, the objective is to minimize the sum of the resulting costs of the decisions implemented at each period, the signal/noise ratio, $\mathrm{S} / \mathrm{N}$, will be measured by (1), where $y$ is the robust indicator (Taguchi 1987).

$S / N=-10 \log \left(\sum \frac{1}{n} y_{i}^{2}\right)$

\section{LP model and tactical planning simulator}

\subsection{LP model}

The model described below is a classical linear program such as those used in advanced planning systems. It represents a decision situation in which loads and capacities have to be adjusted through a SC.

\subsubsection{Indexes}

$h$ : horizon of the tactical plan

$t$ : index of the period of the plan $t=1,2 \ldots, h$

$l$ : index for location, $w$ for warehouses, $p$ for plants, and $s$ for suppliers 
$i$ : index for item, $g$ for finished goods, $c$ for components, and $m$ for raw materials

\subsubsection{Parameters}

$F_{\text {wgt }}$ : demand forecast for period $t$ calculated in warehouse $w$ for finished good $g$

$V_{i}$ : volume of item $i$ expressed in volume unit

$S_{l i}$ : storage volume of item $i$ at location $l$ expressed in units of capacity

$t_{l}$ : maximum number of overtime hours at location $l$ per operator

$x_{l}$ : number of regular hours per operator at location $l$

$W_{l i}$ : number of hours to produce an item $i$ at location $l$

$W_{w}$ : capacity of warehouse $w$ expressed in volume units

\subsubsection{Variables}

$I_{l i t}$ : inventory at the end of period $t$ in location $l$ for item $i$

$B_{w g t}:$ backorders at the end of period $t$ in warehouse $w$ for finished good $g$

$R_{\text {lit: }}$ quantity of item $i$ received in period $t$ at location $l$

$T_{\text {klit: }}$ quantity of item $i$ transported in period $t$ from location $k$ to location $l$

$Q_{\text {lit: }}:$ quantity of item $i$ produced in period $t$ at location $l$

$O_{I t}$ : number of operators at location $l$ in period $t$

$H_{l t}$ : number of operators hired at location $l$ in period $t$

$L_{l t}$ : number of operators laid off at location $l$ in period $t$

$T_{l t}$ : number of overtime hours at location $l$ in period $t$

\subsubsection{Costs}

$C s_{l i}$ : cost of storage per unit of item $i$ at location $l$

$C b_{w g}:$ cost of backorders per unit of finished good $g$ at warehouse $w$

$C T_{k l i}$ : cost of transportation from location $k$ to location $l$ per unit of item $i$

Cpli: cost of production per unit of item $i$ at location $l$ 


\section{P. Genin et al.}

$C w_{l}$ : wages per operator per period at location $l$

$C h_{l}$ : cost of hiring an operator at location $l$

$C l$ : layoff cost of an operator at location $l$

$C t_{l}$ : cost per overtime hour at location $l$

\subsubsection{Objective function}

The objective function (2) is computed from of storage and backorders costs at warehouses, transportation costs from plants to warehouses, costs of plants (storages, production, wages, etc.), and transportation costs from supplying facilities to plants and costs of facilities producing the raw materials (storages, production, wages, etc.).

$$
\begin{aligned}
& \sum_{w, g, t} C s_{w g} \times I_{w g t}+C b_{w g} \times B_{w g t}+\sum_{p, w, g, t} C T_{p w g} \times T_{p w g t}+ \\
& \sum_{p}\left(\sum_{g, t}\left(C s_{p g} \times I_{p g t}+C p_{p g} \times Q_{p g t}\right)+\sum_{t}\left(C s_{p c} \times I_{p c t}+C w_{p} \times O_{p t}+C h_{p} \times H_{p t}+C l_{p} \times L_{p t}+C t_{p} \times T_{p t}\right)\right)+ \\
& \sum_{s, p, c, t} C T_{s p c} \times T_{s p c t}+ \\
& \sum_{s}\left(\sum_{t} C s_{s c} \times I_{s c t}+C p_{s c} \times Q_{s c t}+C s_{s m} \times I_{s m t}+C w_{s} \times O_{s t}+C h_{s} \times H_{s t}+C l_{s} \times L_{s t}+C t_{s} \times T_{s t}\right)
\end{aligned}
$$

\subsubsection{Constraints}

$$
\begin{aligned}
& I_{w g t-1}-B_{w g t-1}+R_{w g t}-F_{w g t-1}=I_{w g t}-B_{w g t} \forall t, g, w \\
& \sum_{k} T_{k l i t}=R_{l i t+1} \forall t, i, l \\
& I_{l i t-1}+Q_{l i t}-\sum_{k} T_{l k i t}=I_{l i t} \forall t, i, l \\
& I_{l j t-1}+R_{l j t}-\sum_{i} Q_{l i t}=I_{l j t} \forall t, l \\
& O_{l t-1}+H_{l t}-L_{l t}=O_{l t} \forall t, p \\
& \sum_{g} I_{w g t} \times V_{g} \leq W_{w} \forall t, w
\end{aligned}
$$




$$
\begin{aligned}
& \sum_{i} I_{l i t} \times V_{i} \leq P_{l i} \forall t, l \\
& T_{l t} \leq t_{l} \times O_{l t} \forall t, l \\
& \sum_{l} W_{l i} \times Q_{l i t} \leq x_{l} \times O_{l t}+T_{l t} \forall t, l \\
& \sum_{i} Q_{l i t} \leq I_{l j t-1} \forall t, l
\end{aligned}
$$

Equations (3), (4), (5), (6), and (7) are respectively inventory balance at warehouses, transportation balance and transportation delay (one period) at location $l$ for item $i$, inventory balance of item $i$ produced at location $l$, inventory balance of item $j$ received at location $l$, and operator balance at location $l$. Equations (8), (9), (10), and (11) represent respectively capacity constraint at warehouses, storage constraint at location $l$, overtime constraint, and capacity constraint at plants. Equation (12) models component availability constraint, bill of materials hypothesis, and production lead-time of one period.

\subsection{Tactical planning simulator}

[Insert figure 4 about here]

At each period $p$, the tactical plan is established by optimization with Cplex, the LP solver from ILOG. When this plan is calculated, the first period, $p$, of this plan is implemented (production, transportation, and hiring or overtime). The actual demand for period $p$ in warehouse $w$ for finished good $g$ is established from the estimated demand from period $F_{w g t}$, to which we add a noise. This noise is a random number that follows a normal distribution with a mean equal to 0 and a standard deviation equal to a quarter of $F_{w g t}$. The choice of this standard deviation corresponds with an interval in which the actual demand ranges between 0 and 2 times the forecast. Knowing the actual demand, the costs of 


\section{P. Genin et al.}

implemented decisions for period $p$ are calculated. The change between the forecasted plan and the actual plan is overstock or backorders due to the forecast error.

To do the next iteration, new forecasts have to be calculated (Figure 4). A single exponential smoothing has been used. Another forecasting method could lead to better forecasts, but because we are seeking to study robustness, we must create a sufficient degree of uncertainty in order to generate some variability. The smoothing constant was fixed at 0.3. As Lee and Yu showed in their work, by fixing the constant at this level, the forecasts are sensitive to changes in the demand (Lee and Yu 1997).

\section{Experimental design, results, and analysis}

We first describe the context in which we use experimental design to define "robust" policies. Those experimental designs are explained in the second part, and the results are analyzed in the last one.

\subsection{The studied supply chain: Vallourec automotive division}

The Vallourec Group is a world leader in the production of seamless steel tubes and components for all industries. Vallourec's automotive and industry division produces tubular products to satisfy the needs of equipment manufacturers and automakers.

[Insert figure 5 about here]

This division can be modeled as a three-level multi-facilities supply chain (see Figure 5). The first plant, which is called "the supplier," produces welded tubes from slabs for two factories. These two factories draw the tubes through a series of dies of decreasing diameter until the desired gauge is attained. The products are stored in warehouses located near the 


\section{Multi-facilities Tactical Planning Robustness}

customers for just-in-time deliveries using a vendor management inventory policy. We will focus on the two main families of cold-drawn tubes.

The studied SC is consequently composed of one supplier of raw material, two plants, two warehouses, and two products $(g=2, n=1, m=2, o=2)$. This case must be considered as a benchmark. We studied with it four policies to demonstrate if it is possible to find one combination that improves robustness. The undertaken experimental design tries to give some answers on the policies to implement in Vallourec's SC to induce some robustness. Once we demonstrated this property on this benchmark, we could evaluate that combination of policies in others contexts.

\subsection{Decision making description and experimental design}

We study the impact of four main different parameters and policies and their effect on the total cost robustness on demand variability. The policies we analyze are the main "tactics" from which supply chain managers can generally choose to establish their tactical plans:

- Factor A: hiring and layoff costs, the human resource policy. At Level 1, hiring and layoff costs are arbitrarily high in such way the solver will stabilize workforce level. At level 2, they are low so as to allow flexibility in labor quantity.

- Factor B: inventory costs in warehouses, which influence inventory policy. At level 1, they are low to allow inventory build-up if necessary. At level 2, they are high in order to drive the solver to establish a low inventory policy.

- Factor C: backorder costs in warehouses, service level policy. With low backorder costs (level 1) the solver will authorize backorders if necessary and will conduct to poor-level service. With high costs, the solver will not allow backorders and then helps to maximize this indicator. 


\section{P. Genin et al.}

- Factor D: overtime costs in supplier and plants, the capacity policy. If theses costs are at a high level, the solver prevents the manager from using extra-capacity (level 1). At a low level (level 2), the solver will proposes to the decision-maker to use overtime if necessary.

The first objective is to find the trade-off that gives a good compromise on robustness and costs among these four policies. Another objective is to understand the effect of these factors and consequently to establish some guidelines (best practices) useful for the managers.

[Insert figure 6 about here]

We used the $\mathrm{L}_{8}\left(2^{7}\right)$ table (see Figure 6 ) to execute our experimental design because we used 4 factors with 2 levels and choose to study 3 interactions. We made 10 replications of the same experiment in order to measure the variability caused by demand with the same set of parameters. The signal/noise ratio can then be measured (see Figure 7).

[Insert figure 7 about here]

\subsection{Results and analysis}

The experiment results are given in Figure 7 and the effect of the different policies are given in Figure 8.

[Insert figure 8 about here]

The range is the difference between the largest and the smallest values observed for an experiment.

The effects are calculated as the difference between the total cost average and the average of the experiments at the modality level. 


\section{Multi-facilities Tactical Planning Robustness}

It is interesting to observe that for the "backorder cost," that is, factor $\mathrm{C}$, the one concerning modality 2 leads to a significant minimization of tactical planning cost. The analysis of the $\mathrm{S} / \mathrm{N}$ ratio shows that this modality is a good choice because the higher this ratio, the better the solution. This modality also reduces the range indicator.

A variance analysis has been performed using the software PlanExpert. The results are shown in Figure 9. Because the differences between the levels of modalities of each factor are in the same range, factor C's influence is considered as significant. Interaction AC is also significant.

[Insert figure 9 about here]

These results show that factor $\mathrm{C}$ and factor A should respectively be fixed at modality 2 and 1 to reduce the tactical plan costs and to increase robustness in obtaining these costs. That can be accomplished by choosing a policy with a stable level of operators and high service level. The other factors do not influence significantly the result and can be fixed according to the manager's wishes. Consequently, an equation can be written to approximate the optimal value given by the studied system: minimum average cost $=$ average $+\mathrm{A} 1+\mathrm{B} 1+$ $\mathrm{C} 2+\mathrm{D} 1$

This means that if managers choose these factor modalities, they will obtain the following minimum average cost for their tactical plan: minimum average cost $=27064-360-160$ $6618-186=19740$.

An experiment of confirmation was run with a new set of demands to corroborate these results. This experiment gives an average of 19821, a standard deviation of 919, and an S/N ratio equal to -8.6 . 


\section{P. Genin et al.}

The very low difference between the predicted optimal cost and the cost obtained by the experiment of confirmation shows that the control factors have an important effect on the average minimum cost. In this case, we can conclude that the parameters for the tactical plan were fixed at good modality levels. Nevertheless, the similar predictive model applied resulted in a standard deviation of 1057. Compared to 919, we can think that some noise factors have an effect on the variability of our system.

To highlight the possible noise factors and to evaluate their effects, we implemented an orthogonal array. We used, as before, an $\mathrm{L}_{8}\left(2^{7}\right)$ table for the controllable factors and an $\mathrm{L}_{4}\left(2^{3}\right)$ table for the chosen noise factors (see Figures 10 and 11); for confidentiality reasons, we present here only two noise factors: transportation and production costs. These factors are effectively uncontrollable because they vary in accordance with the oil or energy costs, and consequently they affect, in an unpredictable way, manager strategies.

[Insert figures 10 and 11 about here]

Figure 12 shows the effects of the controllable and noise factors on the cost of the plans. We can easily observe that the effects of the controllable factors are the same as before. We observe also that the noise factors affect robustness differently: an increase of transportation costs leads to a small increase of the plan cost but increases the variability and the range of the total costs; production costs influence highly the average cost of the plan without having an impact on variability. We note that the ratio $\mathrm{S} / \mathrm{N}$ is the same for these two factors: the $\mathrm{S} / \mathrm{N}$ ratio depends on the effect on the range for $\mathrm{A}^{\prime}$, whereas it is influenced by the average for B'.

[Insert figure 12 about here] 


\section{Multi-facilities Tactical Planning Robustness}

The result of such experimental design, taking into account noise factors, leads to comparing different policies in terms of their total costs and also their impact in terms of robustness. These experiments lead us to establish several equations that describe the behavior of Vallourec's supply chain. These equations are used to compare tactical plans during the sales and operations plan process.

\section{Conclusion}

In this paper, we point out the importance of tactical planning to find optimal priorities and global resource capacities but we also give a robust plan.

We use an experimental design to study the influence of different policies on tactical planning cost robustness. It is implemented for a multi-facilities supply-chain of Vallourec that has been used as a benchmark. We find for it policies' modalities that allow minimizing total costs while increasing cost robustness to demand variability in that context. Future works could extend our work to others benchmarks and try to establish "best practices" for tactical plans according to economic context parameters and enterprise typology.

These management policies take into account decision variables and noise factors. Nevertheless, the main difficulty consists in establishing factor modalities, especially when these values must be regularly updated because of unpredictable cost variations.

Hence, new techniques of dynamic calculation of the tactical plan must be envisaged, as our analysis work has shown, by using a robust optimization. Because of the human, financial, and strategic constraints induced by tactical planning, the optimization criteria as well as the optimization model will need to be adapted in order to increase robustness of a 


\section{P. Genin et al.}

tactical plan in another environment than that studied. Further works must be done in that direction.

\section{References}

Artigues, C., Billaut, J.C., and Esswein, C. Maximization of solution flexibility for robust shop scheduling, European Journal of Operational Research, 2005, 165(2), 314-328.

Blackburn, J.D., Kropp, H.D., and Millen R.A. Comparison of strategies to dampen nervousness in MRP systems, Management Science, 1986, 32(4), 413-429.

Carlson, R.C., Beckman, S.L., Kropp, D.H., The effectiveness of extending the horizon in rolling production schedules, Decision Sciences, 1982, 13(1), 129-146.

Chen, F., Drezner, Z., Ryan, J., and Simchi-Levi, D. The bullwhip effect: Managerial insights on the impact of forecasting and information on variability in a supply chain. In Quantitative Models for Supply Chain Management, edited by S. Tayur, R. Ganeshan, and M. Magazine, pp. 418-437, 1998 (Kluwer Academic Publishers: Dordrecht).

Croom, S., Romano, P., and Giannakis, M. Supply chain management: An analytical framework for critical literature review, European Journal of Purchasing \& Supply Management, 2000, 6, 67-83.

De Kok, A. G., and Inderfurth, K. Nervousness in inventory management: Comparison of basic control rules, European Journal of Operational Research, 1997, 103, 55-82.

Davenport, A.J., and Beck, J.C. A survey of techniques for scheduling with uncertainty, Available online at: www-poleia.lip6.fr/ sourd/gotha/index.html (accessed 01 January 2000).

Durieux, S., and Pierreval, H., Comparison of several design solutions of a real industrial manufacturing system using simulation and risk analysis, in Industrial Engineering and Production Management conference, 2003, 2, 145-154.

Fowlkes, W. Y., and Creveling, C. M. Engineering methods for robust product design: using Taguchi methods ${ }^{\circledR}$ in technology and product development, Ed. Addison-Wesley, $2^{\text {ème }}$ edition, 1997.

Fleischmann, B., Meyr, H., and Wagner, M. Advanced planning. In Supply Chain Management and Advanced Planning, edited by H. Stadtler and C. Kilger, pp. 57-71, 2000 (Springer-Verlag: Berlin).

Forrester, J. W. Industrial Dynamics, 1961 (MIT Press: Cambridge, MA). 
Jensen, T., Measuring and improving planning stability of reorder point lot-sizing policies, International Journal of Production Economics, 1993, 30-31, 167-178.

Heisig, G., Planning stability under (s, S) inventory control rules, OR Spektrum, 1998, 20(4), 215-228.

Ho, C., Evaluating the impact of operating environments on MRP system nervousness, International Journal of Production Research, 1989, 27, 1115-1135.

Kadipasaoglu, S.N., Sridharan, V., Alternative approaches for reducing schedule instability in multi-stage manufacturing under demand uncertainty, Journal of Operations Management, 1995, 13, 193-211.

Kleijnen, J. P.C., and Gaury, E. Short-term robustness of production management systems: A case study, European Journal of Operational Research, 2003, 148, 452-465.

Koltaï, T., and Terlaky, T. The difference between the managerial and mathematical interpretation of sensitivity analysis results in linear programming, International Journal of Production Economics, 2000, 65, 257-274.

Landeghem, H., and Vanmaele, H. Robust planning: A new paradigm for demand chain planning, Journal of Operations Management, 2002, 319, 1-15.

Lasserre J.B., and Mercè C., Robust hierarchical production planning under uncertainty, Annals of Operations Research, 1990, 26, 73-87.

Lee, J. H., and $\mathrm{Yu}, \mathrm{Z}$. H. Worst-case formulations of model predictive control for systems with bounded parameters, Automatica, 1997, 33, 765-781.

Leung, S.C.H, and $\mathrm{Wu}, \mathrm{Y}$. A robust optimization for stochastic aggregate production planning, Production Planning \& Control, 2004, 15(5), 502-514.

Lim J. M., Kim, K. S., Yum, B. J., and Hwang, H. Determination of an optimal configuration of operating policies for direct-input-output manufacturing systems using the Taguchi method, Computers Industrial Engineering, 1996, 31, 555-560.

Mezgar, I., Egresits, CS., and Monostori, L. Design and real-time reconfiguration of robust manufacturing systems by using design of experiments and artificial neural networks, Computers in industry, 1997, 33, 61-70.

Minifie, J.R., Davis, R.A., Interaction effects on MRP nervousness, International Journal of Production Research, 1990, 28, 173-183.

Mulvey, J. M., and Ruszczynski, A. A new scenario decomposition method for large-scale stochastic optimization, Operations Research, 1995, 43(3), 477-490. 
Mulvey, J. M., Vanderbei, R. J., and Zenios, S. A. Robust optimization of large-scale systems, Operations Research, 1995, 43(2), 264-281.

Orlicky, J. Material Requirements Planning, 1975, (McGraw-Hill).

Pujawan, I. N. Schedule nervousness in a manufacturing system: A case study, Production Planning \& Control, 2004, 15(5), 515-524.

Shang, J. S., Li, S., and Tadikamalla, P. Operational design of a supply chain system using the Taguchi method, response surface methodology, simulation, and optimization, International Journal of Production research, 2004, 42(8), 3823-3849.

Sridharan, S.V., Laforge, R.L., An analysis of alternative policies to achieve schedule stability, Journal of Manufacturing and Operations Management, 1990, 3, 53-73.

Stadtler, H., and Kilger, C. Supply Chain Management and Advanced Planning: Concepts Models, Software and Case Studies, 2000 (Springer-Verlag: Berlin).

Taguchi, G. Orthogonal arrays and linear graph, 1987 (American Supplier Institute Press: Livonia, MI).

Towill, D. R. Supply chain dynamics, International Journal of Computer Integrated Manufacturing, 1991, 4(4), 197-208.

Roy B. A missing link in OR-DA: robustness analysis, Foundations of Computing and Decision Sciences, 23, 1998, 141-160.

Van Donselaar, K., Van Den Nieuwenhof, J., and Visschers, J. The impact of material coordination concepts on planning stability in supply chains, International Journal of Production Economics, 2000, 68, 169-176.

Vollmann, T. E., Berry, W. L., and Whybark, D. C. Manufacturing Planning And Control Systems, 4th ed., 1997 (McGraw-Hill: New York).

Walter, D. Performance planning and control in virtual business structures, Production Planning \& Control, 2005, 16(2), 226-239.

Yano, C.A., Carlson, R.C., Interaction between frequency of rescheduling and the role of safety stock in material requirements planning systems, International Journal of Production Research, 1987, 25, 221-232.

$\mathrm{Yu}$, C.-S., and Li, H.-L. A robust optimization model for stochastic logistic problems, International Journal of Production Economics, 2000, 64, 385-397. 
Zäpfel G. Customer-order-driven production: an economical concept for responding to demand uncertainty, International Journal of Production Economics, 56/57, 1998, 699709 .

Zhao, X., Lee, T.S., Freezing the master production schedule for material requirements planning systems under demand uncertainty, Journal of Operations Management, 1993, 11(2), 185-205.

Figure 1. Experimental design according to Taguchi (Taguchi 1987)

Figure 2. Three-level supply chain

Figure 3. Simplified tactical planning process

Figure 4. Simulation process

Figure 5. Vallourec's automotive and industry supply chain

Figure 6. Experimental design

Figure 7. Experimental design results

Figure 8. Effects of the studied factors on the different indicators

Figure 9. Variance analysis with PlanExpert software

Figure 10. P-diagram of tactical plans simulator

Figure 11. Orthogonal array

Figure 12. Effects of the controllable and noise factors on the different indicators 


\section{P. Genin et al.}

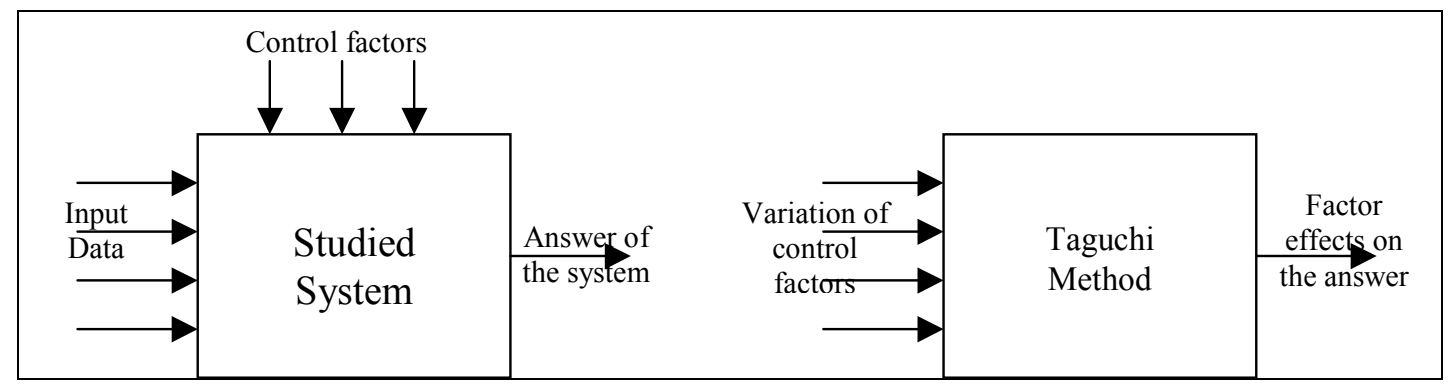

Figure 1. Experimental design according to Taguchi (Taguchi 1987)

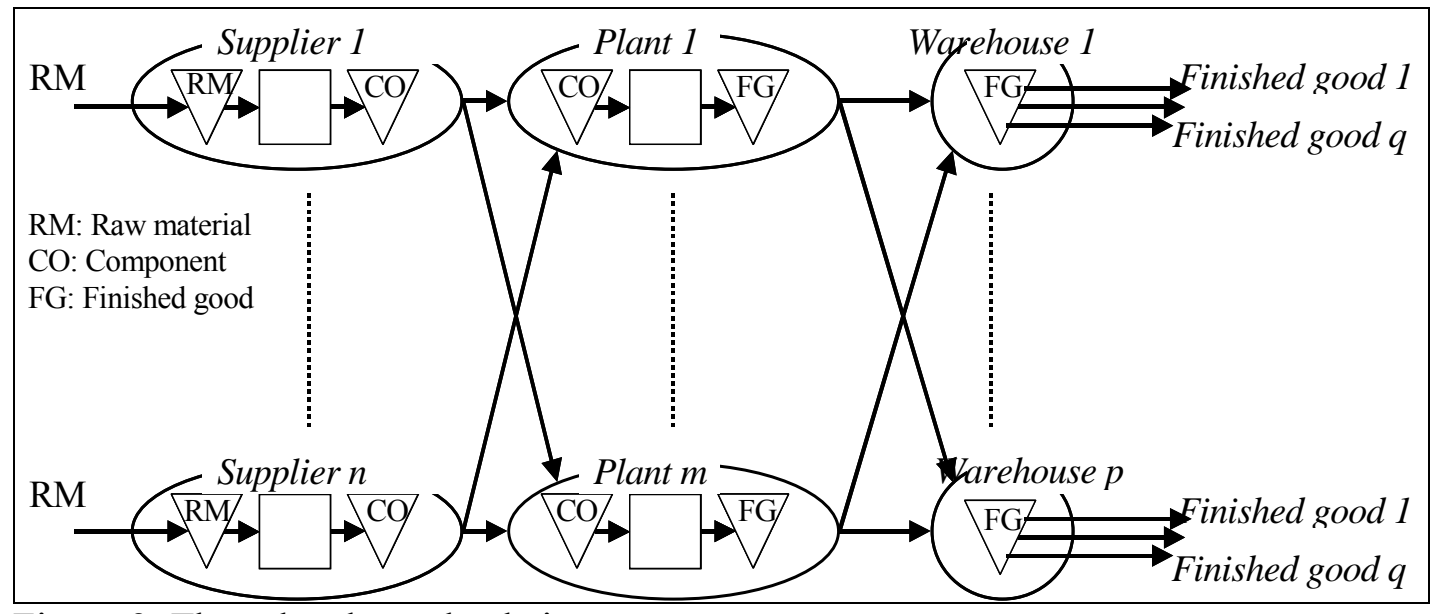

Figure 2. Three-level supply chain

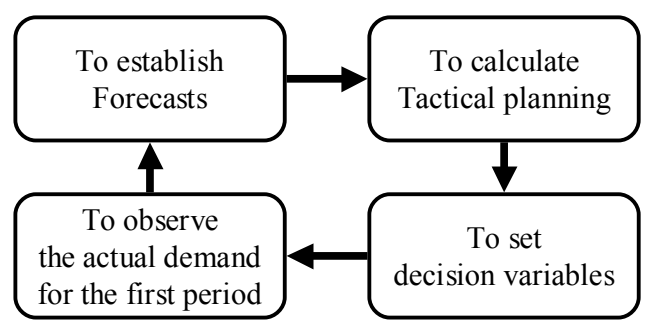

Figure 3. Simplified tactical planning process

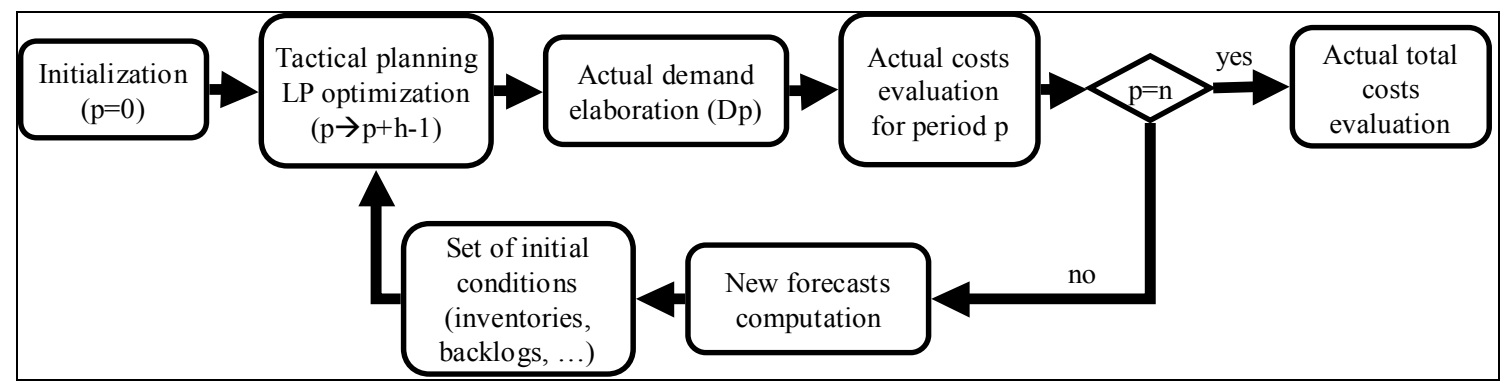

Figure 4. Simulation process 


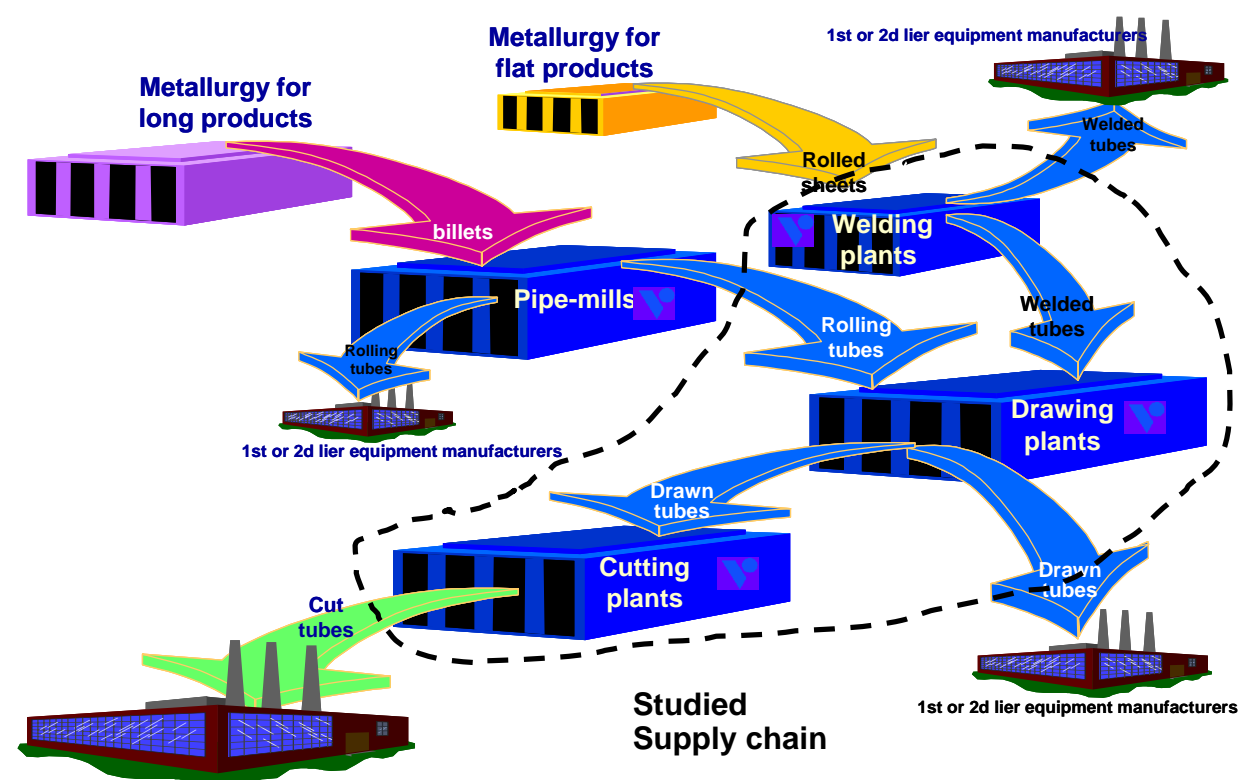

1st or 2d lier equipment manufacturers

Figure 5. Vallourec's automotive and industry supply chain

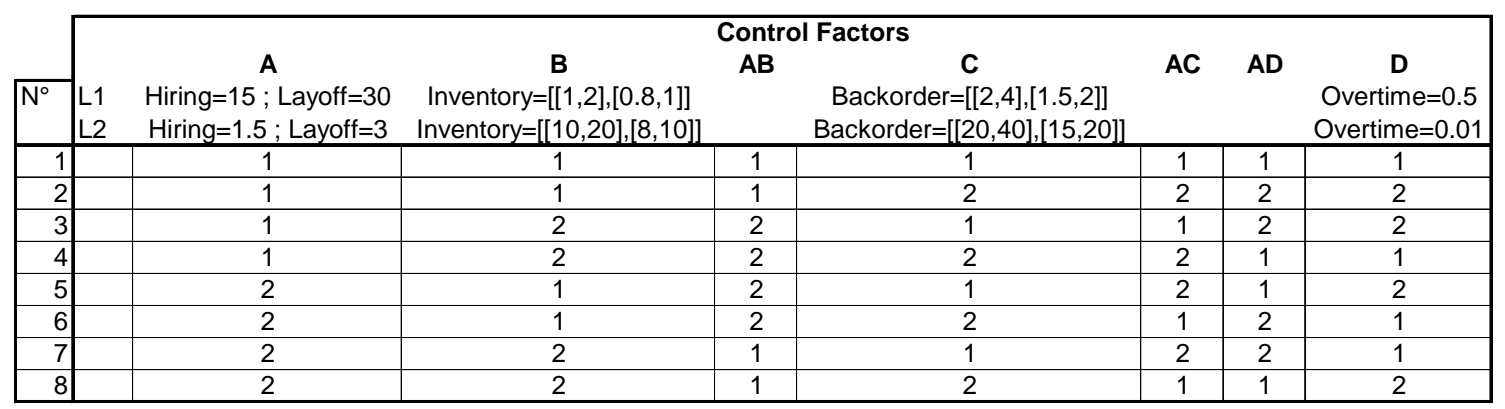

Figure 6. Experimental design

Results of experiments

\begin{tabular}{|c|c|c|c|c|c|c|c|c|c|c|c|c|c|c|}
\hline \multirow{2}{*}{\multicolumn{10}{|c|}{ Total real costs }} & \multirow{2}{*}{\multicolumn{2}{|c|}{$\begin{array}{c}\text { Mean of } \\
\text { experiments }\end{array}$}} & \multirow{2}{*}{$\begin{array}{l}\text { Standard } \\
\text { Deviation }\end{array}$} & \multirow[b]{2}{*}{ Range } & \multirow[b]{2}{*}{$S / N$ ratio } \\
\hline 1 & & & & & 6 & 7 & 8 & 9 & 10 & & & & & \\
\hline 32040 & 36033 & 30683 & 36892 & 31750 & 31945 & 35436 & 33942 & 36318 & 32672 & R1 & 33771 & 2244 & 6210 & $-9,06$ \\
\hline 18361 & 19725 & 18902 & 22805 & 18696 & 18328 & 19506 & 20602 & 21103 & 19246 & R2 & 19727 & 1413 & 4477 & $-8,59$ \\
\hline 31975 & 35998 & 30657 & 36735 & 31745 & 31918 & 35433 & 33920 & 36234 & 32608 & R3 & 33722 & 2221 & 6077 & $-9,06$ \\
\hline 18293 & 19508 & 18788 & 22185 & 18704 & 18499 & 19447 & 20366 & 21056 & 19145 & R4 & 19599 & 1248 & 3891 & $-8,59$ \\
\hline 31742 & 35743 & 30525 & 36594 & 31799 & 31925 & 35356 & 33813 & 35953 & 32595 & R5 & 33605 & 2165 & 6069 & $-9,05$ \\
\hline 18871 & 20991 & 19635 & 23247 & 19478 & 19191 & 20137 & 21519 & 21933 & 20132 & R6 & 20513 & 1387 & 4376 & $-8,63$ \\
\hline 31857 & 35885 & 30553 & 36528 & 31843 & 31927 & 35500 & 33763 & 36070 & 32392 & R7 & 33632 & 2191 & 5975 & $-9,06$ \\
\hline 20204 & 22188 & 20990 & 24954 & 20617 & 20533 & 21564 & 23080 & 23702 & 21556 & R8 & 21939 & 1545 & 4749 & $-8,68$ \\
\hline
\end{tabular}

Figure 7. Experimental design results 

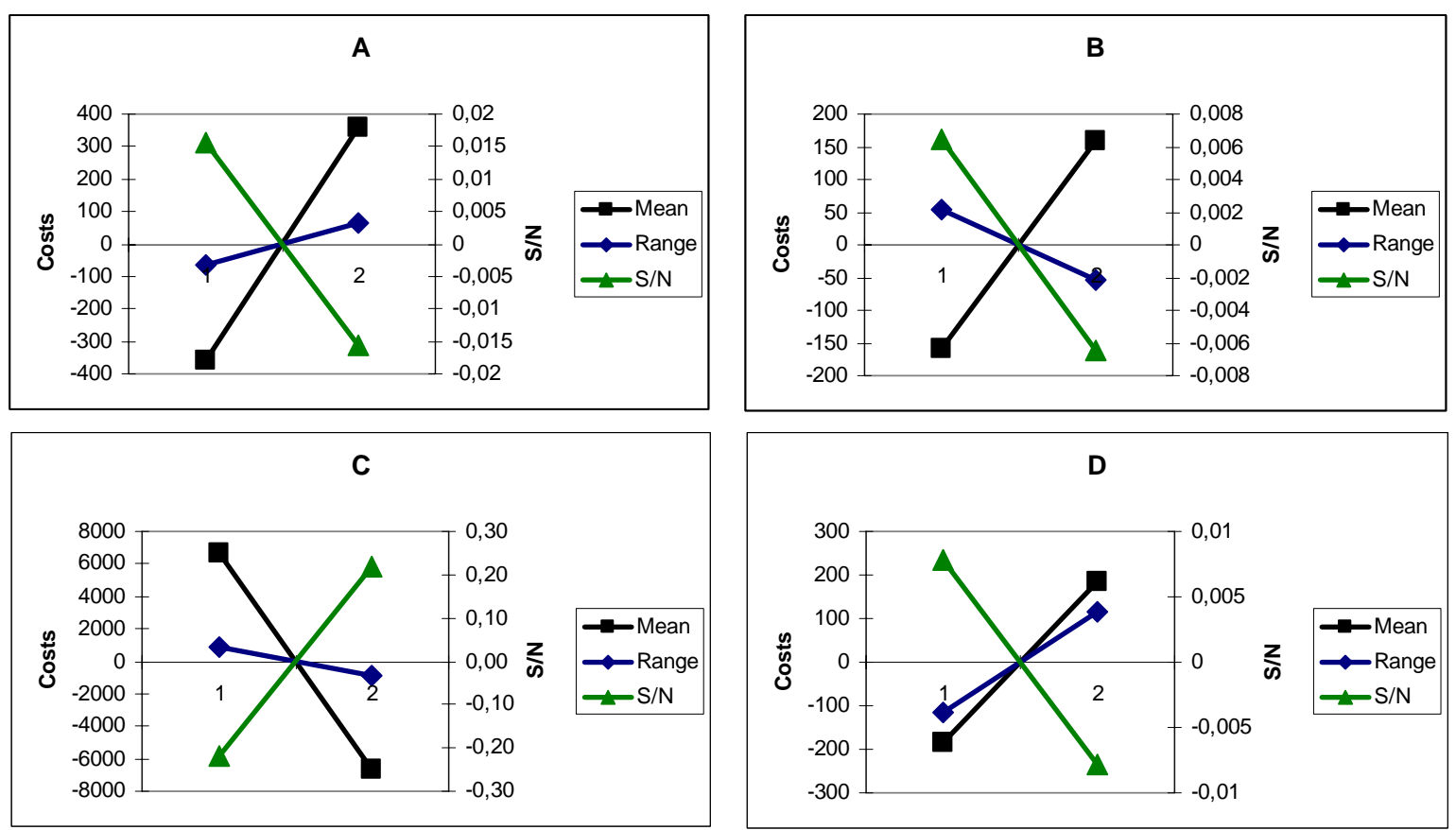

Figure 8. Effects of the studied factors on the different indicators

\begin{tabular}{|c|r|r|r|r|r|r|r||}
\hline \multicolumn{1}{|c|}{ Moyenne } & \multicolumn{2}{c|}{ Variance } & \multicolumn{3}{|c|}{ Signal/Bruit } \\
\hline Actions & \multicolumn{1}{|c|}{ S. des carrés } & \multicolumn{1}{c|}{ DDL } & \multicolumn{1}{c|}{ Variance } & \multicolumn{1}{c|}{ F } & Q[F & Sig. \\
\hline A & 10286082,4500 & 1 & 10286082,4500 & 3,0124 & 0,0869 & \\
\hline B & 2033944,2000 & 1 & 2033944,2000 & 0,5957 & 0,4428 & \\
\hline C & 3504760501,0000 & 1 & 3504760501,0000 & 1026,4193 & 0,0000 & S \\
\hline D & 2173382,4500 & 1 & 2173382,4500 & 0,6365 & 0,4276 & \\
\hline A.B & 3320310,0500 & 1 & 3320310,0500 & 0,9724 & 0,3274 & \\
\hline A.C & 14304169,8000 & 1 & 14304169,8000 & 4,1892 & 0,0443 & S \\
\hline A.D & 2729127,2000 & 1 & 2729127,2000 & 0,7993 & 0,3743 & \\
\hline Résidus & 245847626,4000 & 72 & 3414550,3670 & & & \\
\hline Total & 3785455144,0000 & 79 & & & & \\
\hline \hline
\end{tabular}

Figure 9. Variance analysis with PlanExpert software 
Multi-facilities Tactical Planning Robustness

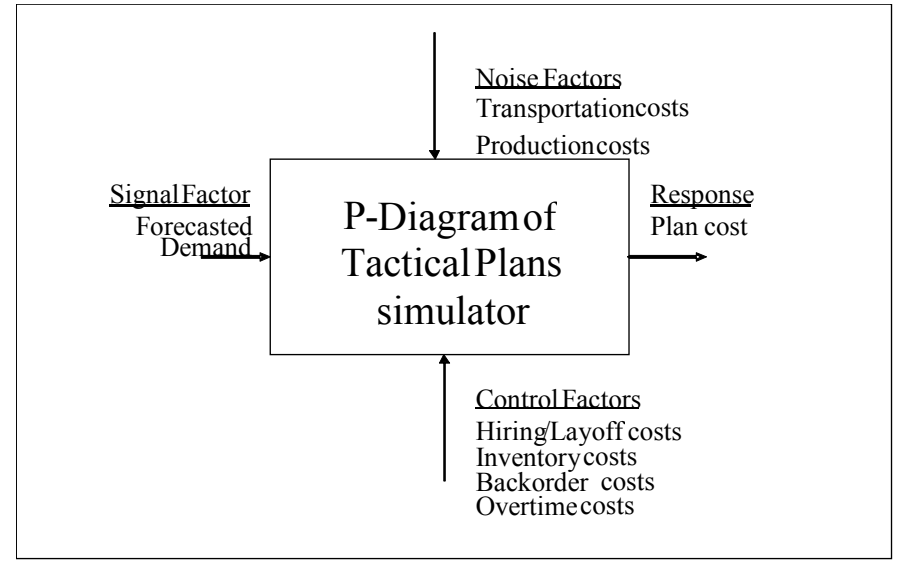

Figure 10. P-diagram of tactical plans simulator

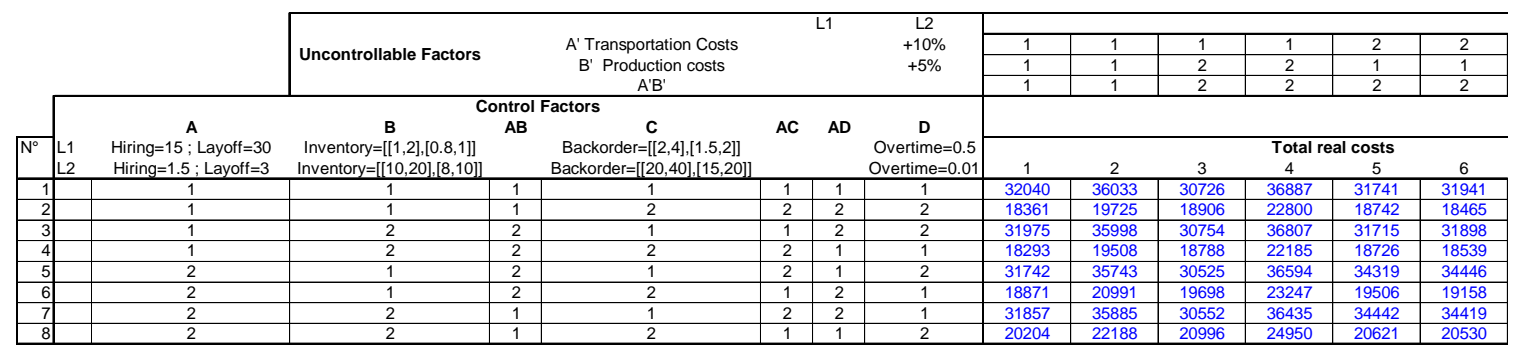

Figure 11. Orthogonal array
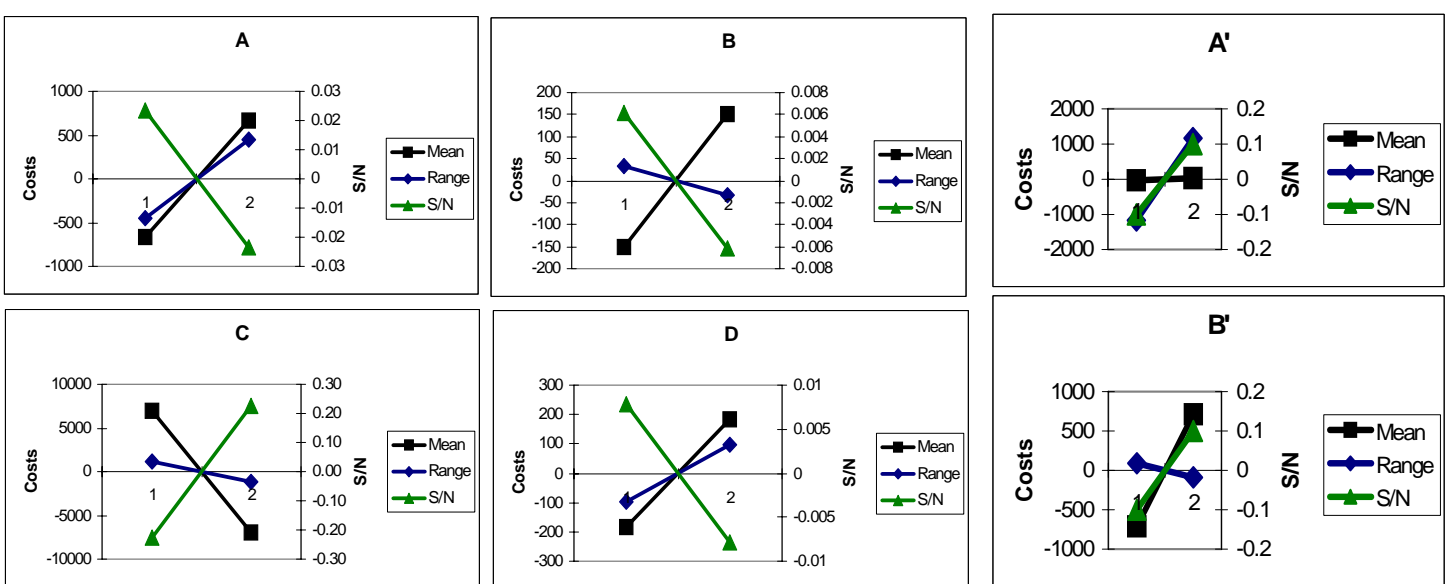

Figure 12. Effects of the controllable and noise factors on the different indicators 